\title{
Variation of Physicochemical and Sensory Properties during the Aging of Yerba Mate
}

\author{
Santiago A. Holowaty ${ }^{a}$, Sergio A. Surkan ${ }^{a}$, Valeria D. Trela ${ }^{a}$, Germán D. \\ ByCZKO $^{\mathrm{a}}$, AND Miguel E. SCHMAlKO ${ }^{\text {** }}$

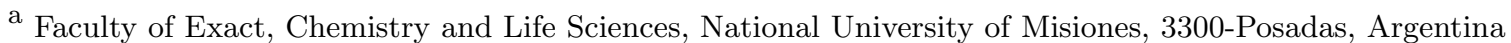 \\ ${ }^{*}$ Corresponding author \\ mesh@fceqyn.unam.edu.ar
}

Received: 27 February 2014; Published online: 18 October 2014

\begin{abstract}
Yerba mate infusion is widely consumed in Argentina, Brazil and Paraguay. One of the processing steps used in Argentina is aging. The following three methods were used to age yerba mate: 1) air humidity and temperature-controlled aging; 2) temperature-controlled aging and 3) no control. The aim of this research was to determine the physicochemical and sensory attribute differences when yerba mate was aged using these three methods. The concentration of caffeine, glucose, fructose, maltose and phenolic compounds and $\mathrm{pH}$ diminished in all three aging methods but by different percentages. The sensory attributes did not exhibit uniform behaviour. Astringency remained constant in the first method and diminished in the other two. Bitterness increased in all three methods but by different percentages. Sweetness diminished in all three methods. Notably few correlations were determined between physicochemical and sensory attributes.
\end{abstract}

Keywords: Ilex paraguariensis; Yerba mate; Sensory evaluation; Chemical compounds; Aging

\section{Introduction}

Yerba mate (Ilex paraguariensis Saint Hilaire) is a tree that grows in the central region of the Mercosur (Argentina, Brazil and Paraguay). Infusions derived from this tree are mainly consumed in this region, but in recent years, consumption of yerba mate infusion has increased in new countries due to its nutritional and functional properties (Bracesco, Sanchez, Contreras, Menini, \& Gugliucci, 2011).

The yerba mate elaboration process is very particular (Schmalko \& Alzamora, 2001). The branches of the tree are collected and thermally treated with the gases from wood-burning to inactivate enzymes that produce leaf browning. Simultaneously, there is a high loss of water. In the next step, the branches are dried using different driers (rotary and continuous and discon- tinuous belt dryers) to reach a moisture content that stabilises the product (Holowaty, Ramallo, \& Schmalko, 2012).

In Brazil, the ground product is subsequently packed for consumption. However, in Argentina and Paraguay, the product is aged to modify its organoleptic properties based on market requirements in these countries. Before that step, the product is coarsely ground and packed in bags of approximately $40 \mathrm{~kg}$ to be aged. Consumer perception is notably different in these countries and is dependent on the method of processing (de Godoy et al., 2013).

For a long time, the product has been aged in warehouses without any temperature or relative humidity controls. The aging period varies between 9 and 24 months (Natural Aging, NA) in different industries. In recent years, new aging 
methods have been developed to reduce the aging period. In the first method, developed in the 1980 s, the temperature and relative humidity of the warehouse is controlled. The aging period is reduced to 30 to 45 days (Air Humidity and Temperature Controlled Aging, HTCA). In the second new method, developed in the 2000s, only the temperature is controlled (Temperature Controlled Aging, TCA), with the mean temperature being approximately $45^{\circ} \mathrm{C}$. In both methods, fans are used to produce forced convection of the air.

In all methods of aging, the end of the process is determined by sensory evaluation by expert panellists. Generally, the panellists use a traditional method of yerba mate consumption, known as "mate". In this operation, the yerba mate (30-50 $\mathrm{g}$ ) is placed in a gourd and fractions of hot water $\left(70-85{ }^{\circ} \mathrm{C}\right)$ are poured over it. To drink the infusion, a device similar to a straw with a filter at one end is used (Scipioni, Ferreyra, Acuna, \& Schmalko, 2010).

The three aging methods produce a product with different tastes that the consumer can differentiate. However, there are no published papers regarding which attributes are different in these products. Several authors have studied the variations of certain components in various manufacturing processes, such as caffeine (Isolabella et al., 2010), but there is no research concerning the variation of components among the different aging methods.

The type and concentration of sugars varied throughout the heat treatment and drying steps. Gomez Vara, Brieux, and Avanza (1979) determined that sugar reduction is approximately 34 $\%$ after these steps. They also observed that the concentration of sugars does not vary during NA. Dartora et al. (2011) found an increase in sugars in the oxidised leaves of yerba mate, which may soften the flavour of the beverage.

Xanthines are a type of purines found in many trees. In yerba mate, theophylline, theobromine and caffeine can be found. Caffeine is the major component, being observed at between 1 and $2 \%$ (in dried bases) (Heck \& De Mejia, 2007; Anesini, Turner, Cogoi, \& Filip, 2012). A major decrease in caffeine content (approximately $30 \%$ ) takes place during the heat treatment and drying steps (Schmalko \& Alzamora, 2001; Isolabella et al.,
2010). This behaviour is different from pigments and sugars that undergo great losses during the heat-treatment step (Bertoni, Kricun, Kanzig, \& Cattaneo, 1992; Schmalko \& Alzamora, 2001). Bertoni et al. (1992) reported losses of approximately $15 \%$ in caffeine content during NA.

Infusions of yerba mate are generally bitter, and this taste is generally related to the caffeine content (Calvino, Fraga, \& Garrido, 2004; Streit et al., 2007). Previous studies conducted with coffee infusions demonstrated that caffeine contributes to 10 and $30 \%$ of bitter perception. Furthermore, recent studies carried out with yerba mate reported that the bitter taste is not only related to the caffeine (Pagliosa et al., 2009). Tea leaves contain large quantities of phenolic compounds. Cathechins (flavonoids) are approximately $30 \%$ of the phenolic compounds and have a high influence on the bitter and astringent tastes (Streit et al., 2007; Pagliosa et al., 2010). Yerba mate has high content of polyphenols, including flavonoids (rutin) and caffeoylquinic acids (chlorogenic acid, 3,5- and 4,5dicaffeoylquinic acids) (Tamasi, Filip, Ferraro, \& Calviño, 2007). Yerba mate also has saponins (Heck \& De Mejia, 2007) and methylxanthines (Pagliosa et al., 2010). All of these compounds can influence the bitter taste and the astringency of the processed yerba mate.

Recently, Anesini et al. (2012) found that the concentration of caffeoylquinic derivatives, methylxanthines and rutin was higher in the processed product than in yerba mate without processing. Others authors reported a decrease in the concentration of methylxanthines in the processed yerba mate and an increase in the quantity of oxidised methylxanthines (Dartora et al., 2011). Several studies related the phenolic compounds to the increase of bitterness (Robichaud \& Noble, 1990). Others (Marquez et al., 2013) have related the bitterness and astringency to the type of phenolic compound, not its concentration. These researchers reported that the bitter taste of yerba mate is an acquired taste, and this taste is most likely due to changes in the type of phenolic compounds.

Santa Cruz, Garitta, and Hough (2002) developed 30 descriptors to define the sensory profile of yerba mate. These authors also studied its acceptability based on these sensory attributes 
(Santa Cruz, Garitta, \& Hough, 2003). However, only three of them are usually used - astringency, bitterness and sweetness.

The knowledge of how the changes in the concentration of compounds relate to the characteristic tastes of yerba mate will help to control the quality of the product during the aging method used during its processing. The objective of this research was to evaluate and relate the physicochemical ( $\mathrm{pH}$ and soluble solids, caffeine, sugars and phenolic compound concentration) and sensory (astringency, bitterness and sweetness) changes produced by the various methods of aging yerba mate.

\section{Materials and Methods}

\subsection{Materials}

A sample of $150 \mathrm{~kg}$ of dried and coarsely ground yerba mate (from Misiones, Argentina) was divided in six parts and put into 6 bags of approximately $25 \mathrm{~kg}$. The bags were then put into three aging warehouses to obtain duplicate measurements. Two of them were put in a NA warehouse for 300 days and samples were taken every 30 days. Others two were put into a warehouse with controlled temperature at $45{ }^{\circ} \mathrm{C}(\mathrm{TCA})$ for 180 days. In a first period of 90 days, samples were taken every 10 days and in a second period of 90 days, samples were taken every 30 days. The last two were put in a warehouse with controlled air humidity at $60 \%$ and temperature at $60{ }^{\circ} \mathrm{C}$ (HTCA) for 50 days In this case samples were taken every 5 days. The experiment was started on April 10 $0^{\text {th }}, 2011$.

From each particular sample, leaves were separated from twigs, and then they were ground separately using a 40 mesh sieve to control the product output. After that, the two fractions (twigs and leaves) were mixed in the proportion $20 / 80$ (twigs to leaves). The sample was then maintained at $-20{ }^{\circ} \mathrm{C}$ until it was used.

To obtain the samples, a solution was extracted using a method that simulates mate consumption. In this assay, $50 \mathrm{~g}$ of yerba mate was put in a glass and $30 \mathrm{ml}$ portions of water at $70{ }^{\circ} \mathrm{C}$ were poured over it. The solution was extracted, under vacuum, until $500 \mathrm{ml}$ was obtained (Scipi- oni et al., 2010). All the determinations (soluble solids, sugars, caffeine and phenolic compounds content and $\mathrm{pH}$ ) were carried out on these solutions.

\subsection{Soluble Solids}

A portion of $100 \mathrm{ml}$ of the solution was evaporated in an oven at $100{ }^{\circ} \mathrm{C}$ until it reached a constant weight (approximately $24 \mathrm{~h}$ ).

\subsection{Sugars (sucrose, glucose, fructose and maltose)}

Sugars were determined using an HPLC method (IRAM 20532). A Waters Model 6000A (USA) chromatograph, an amino column (Altima Alltech Associates, USA), $1.1 \mathrm{ml} / \mathrm{min}$ of a mobile phase of acetonitrile:water (75:25 in volume) and a refraction index detector (Waters 410, Millipore, USA) were used.

\subsection{Caffeine}

Caffeine was determined using an HPLC method (IRAM 20512). A dilute solution (1:10) was injected in a liquid chromatograph Waters Model 6000A (USA). A C18 column (Ultrasphere Beckman, USA), a flux of $1 \mathrm{ml} / \mathrm{min}$ of a mobile phase of acetonitrile:water (20:80 in volume) and a UVvisible detector (Lambda 481, Waters - Millipore, USA) at $254 \mathrm{~nm}$ were used.

\section{$2.5 \mathrm{pH}$ determination}

$\mathrm{pH}$ determination was made using a glasscombined electrode.

\subsection{Phenolic content}

The total polyphenol content (TPC) was determined by a spectrophotometric technique using a UV/Vis spectrophotometer (Spectrum SP-2102, photometric accuracy $0.3 \% \mathrm{~T}$, spectrum bandwidth: $2 \mathrm{~nm}$ ) according to the method described in the international standard ISO 14502. The content was expressed as gallic acid equivalents as a mass percentage of dry matter (GAE; g \% 
$\mathrm{dm})$. One millilitre of the diluted sample extract was transferred in duplicate to separate tubes containing $5.0 \mathrm{ml}$ of water-diluted FolinCiocalteu's reagent $(10 \% \mathrm{v} / \mathrm{v})$. Then, $4.0 \mathrm{ml}$ of sodium carbonate solution $(7.5 \% \mathrm{w} / \mathrm{v})$ was added. The tubes were allowed to stand at room temperature for $60 \mathrm{~min}$ before the absorbance was measured at $765 \mathrm{~nm}$ against distilled water. The concentration of phenolic compounds in samples was derived from a standard curve of gallic acid ranging from 0 to $60 \mu \mathrm{g} / \mathrm{ml}\left(\mathrm{R}^{2}=0.998\right)$. The total polyphenol content in the original extracts (TPCo) was expressed as GAE in $\mu \mathrm{g} / \mathrm{ml}$ of the original extract. Determinations were carried out in duplicate (Hartwig, Brumovsky, \& Fretes, 2012).

\subsection{Sensory Evaluation}

The candidates to form the panel were selected from the students and personnel of the Faculty of Exact, Chemistry and Life Sciences, National University of Misiones; all panellists were selected according to the following criteria: a) they were consumers of yerba mate b) absence of allergies or similar affliction, c) non-smokers, d) people between the ages of 22-55, e) normal perception abilities, f) people available for all sessions, g) people interested in participating, h) performance in sequential tests with the mate extract and i) performance in basic flavour tests. The selection and training of panellists were conducted according to IRAM standards 20005-1 and 2 . Eight panellists were selected from a population of 20 candidates; 2 men and 6 women between 22 and 28 years old.

Sensory evaluation was carried out by these 8 trained panellists. Four samples were presented in coded foam cups in a balanced and random way for each panellist; every cup was provided with a lid and a drinking straw.

Panellists received the four samples and were asked to evaluate one taste per session. They were instructed to evaluate samples by using a score of 1 (lowest intensity) to 10 (highest intensity). Demineralised water was used as a palate cleanser between samples. The analyses were performed in three sessions per taste and aging time.

\subsection{Statistical Analysis}

To compare the data on chemical analysis and sensory evaluation, an ANOVA test with a confidence limit of $95 \%$ was used. A correlation analysis and a principal component analysis were also used. The StatGraphics statistical package (2009) was used to process the data.

\section{Results and Discussion}

\subsection{Physicochemical Changes of the Extract}

The concentration of soluble solids obtained by simulating the mate consumption showed variations of less than $10 \%$. In HTCA, a statistically significant increase of $9 \%$, from $28.02 \pm 0.22$ to $30.55 \pm 0.79 \mathrm{~g} / \mathrm{l}$, was observed. In the other two aging methods (TCA and NA), the variation in the soluble solid concentration was minor and statistically not significant (a decrease of 3.9 and an increase of $2.5 \%$, respectively). The $\mathrm{pH}$ varied between $5.55 \pm 0.05$ and $6.06 \pm 0.06$ during the aging of yerba mate, increasing slightly at the beginning of the aging and decreasing at the end. However, only the NA method showed significant differences $(\mathrm{p}<0.008)$ in the decreased concentration during aging. This finding means that there was an increase in acidity during NA, but this increase was notably low and most likely did not influence sensory tests. In the other two methods (TCA and HTCA), the pH did not vary during aging $(\mathrm{p}<0.249$ and $\mathrm{p}<0.505$, respectively).

The caffeine concentration diminished during aging in the three methods. ANOVA showed a significant difference between the caffeine concentration at the beginning $(0.73 \pm 0.01 \mathrm{~g} / \mathrm{l})$ and at the end of the aging $(\mathrm{p}<0.001)$. In the HTCA method, it diminished by $17 \%$. In the TCA method, it decreased by $42 \%$, and in the NA method by $12 \%$. Similar losses in caffeine content (approximately $15 \%$ ) during NA were reported by Bertoni et al. (1992).

The variations in the monosaccharides fructose (fru) and glucose (glu) are shown in Fig. 1. The variations in the disaccharides sucrose (glu-fru) and maltose (glu-glu) are shown in Fig. 2. The sugar concentration showed many changes dur- 
a)
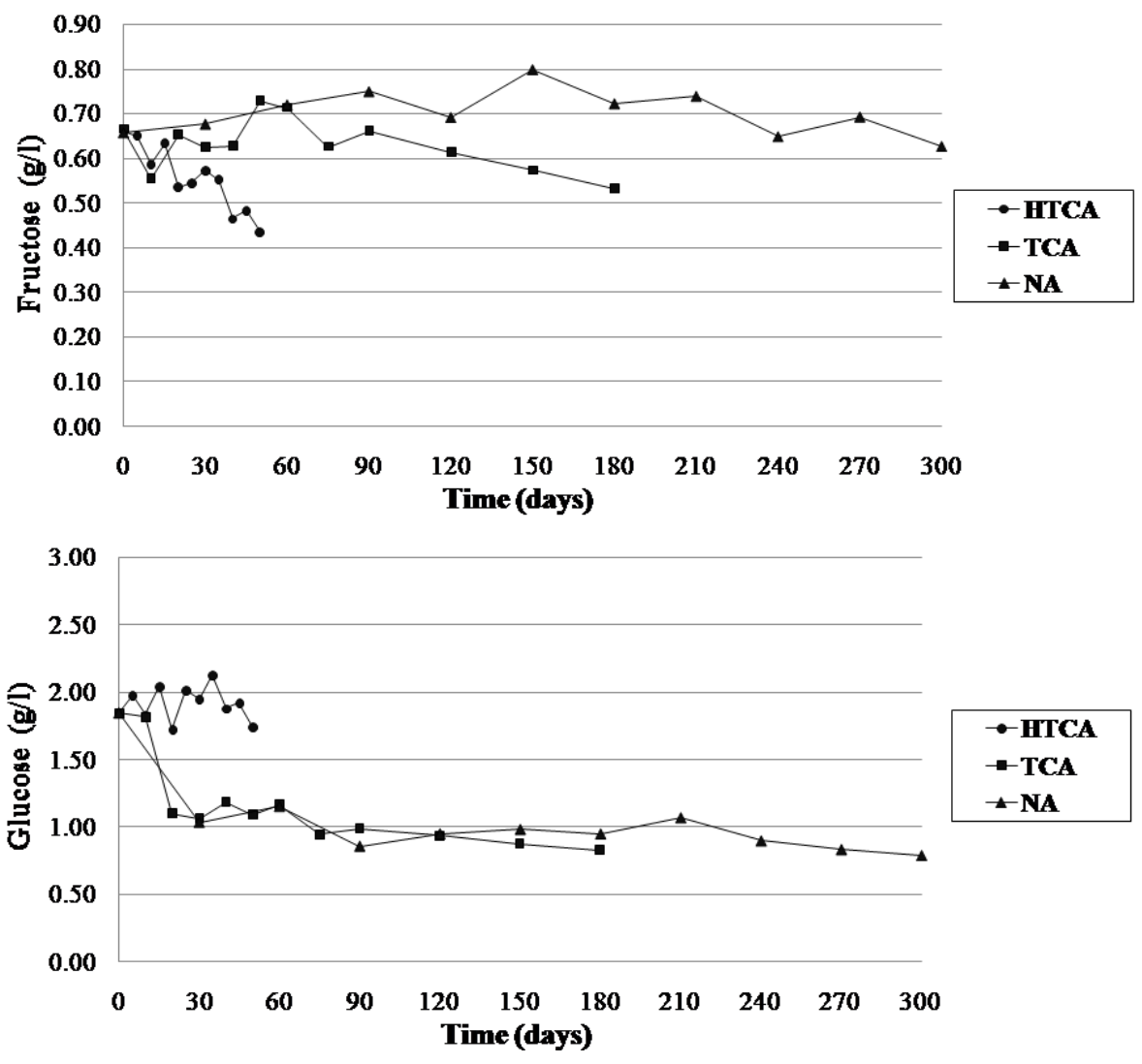

Figure 1: Monosaccharide ( $a=$ Fructose,$b=$ Glucose) concentration variation in the water extract in the three aging methods

ing aging, not only at the end of the aging, but throughout all of it in all three methods.

The fructose concentration decreased in all three aging methods. Its mean initial concentration in the extract was $0.66 \pm 0.02 \mathrm{~g} / \mathrm{l}$, while at the end of NA it was $0.62 \pm 0.04 \mathrm{~g} / \mathrm{l}$, in the TCA it was $0.53 \mathrm{~g} / 1 \pm 0.04$, and the HTCA had the highest decrease, with a final concentration of $0.44 \pm 0.05 \mathrm{~g} / \mathrm{l}$. When the fructose concentration at the end of the three aging methods was compared, significant differences were found between the mean values.

The initial glucose concentration $(1.85 \pm 0.07$ $\mathrm{g} / \mathrm{l})$ was higher than the fructose concentration. In NA $(0.79 \pm 0.03 \mathrm{~g} / \mathrm{l})$ and TCA $(0.83 \pm 0.13$ $\mathrm{g} / \mathrm{l})$, the concentration decreased during aging (Fig. 1). No significant changes were found in the HTCA method $(1.74 \pm 0.09 \mathrm{~g} / \mathrm{l})$ during ag- ing.

Sucrose exhibited a slight increase in the middle period and a slight decrease in the last period (Fig. 2). However, the sucrose concentration at the end of the aging was statistically higher than the initial values. It varied from $2.68 \pm 0.47 \mathrm{~g} / \mathrm{l}$ to $2.82 \pm 0.38 \mathrm{~g} / \mathrm{l}$ in the HTCA method to 2.88 $\pm 0.12 \mathrm{~g} / \mathrm{l}$ in the TCA method and $2.83 \pm 0.19$ $\mathrm{g} / \mathrm{l}$ in the NA method. No differences were found among the final concentrations using the different aging methods.

The maltose concentration $(0.70 \pm 0.01 \mathrm{~g} / \mathrm{l})$ was lower than the sucrose concentration, but was different in the three aging methods. In the HTCA method, it decreased steadily with time. The final concentration was approximately $43 \%$ less than the initial value. In the TCA method, it increased slightly between 30 and 60 days and 
Variation of properties during aging of yerba mate $\mid 233$

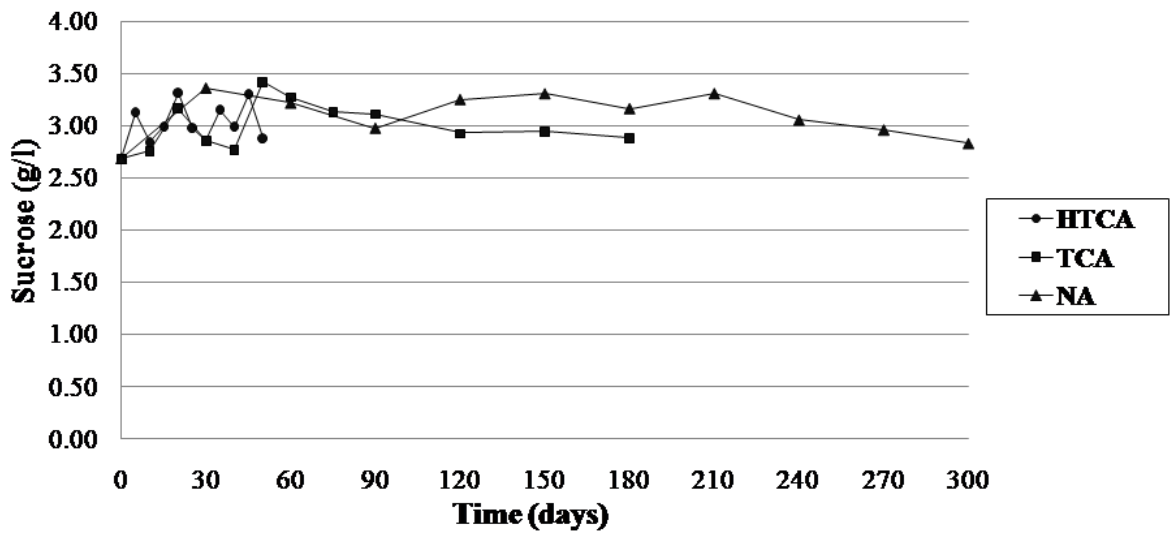

a)

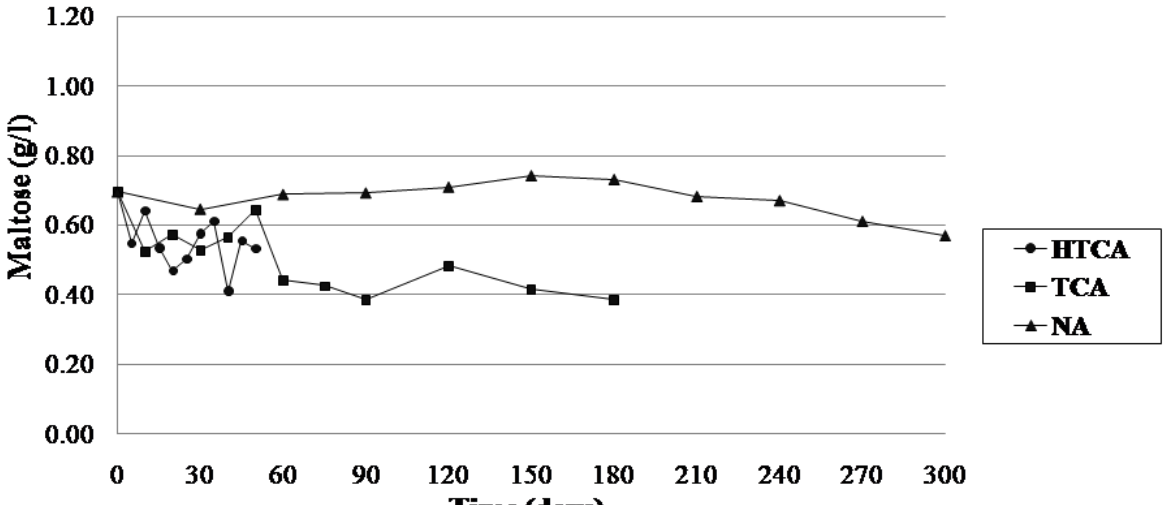

b)

Figure 2: Disaccharide ( $\mathrm{a}=$ sucrose, $\mathrm{b}=$ maltose) concentration variation in the water extract in the three aging methods.

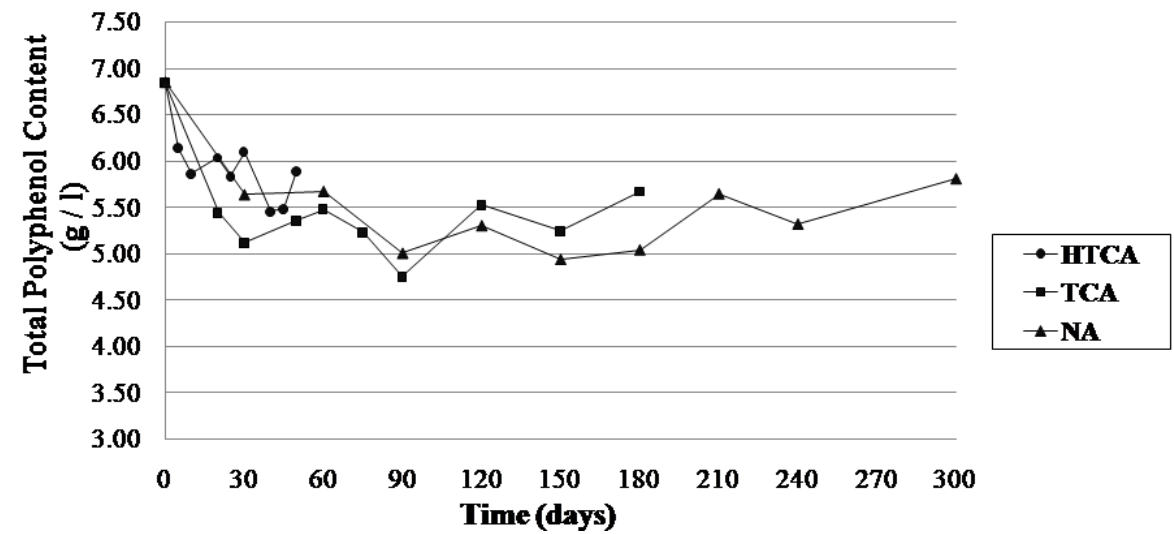

Figure 3: Total polyphenol content variation in the water extract in the three aging methods. 
decreased at the end of the aging. The final concentration was $45 \%$ less than the initial value. In the NA method, intermediate values showed increases of approximately $9 \%$ at day 150 and a slight subsequent decrease, with the final concentration $18 \%$ less than the initial value. The behaviour of maltose in the TCA and NA methods in the intermediate aging periods (a slight increase) was correlated with the decrease in the glucose concentration in this period.

All sugar concentrations can be expressed as sweetness equivalent of sucrose, considering the sweetening power of each individual sugar (sucrose $=100 ;$ fructose $=173.3$; glucose $=74.3$ and maltose $=32$ ). During aging, the sucrose sweetness equivalent concentration diminished by $6 \%$ in HTCA, $16 \%$ in TCA and $13 \%$ in NA. These results differed from those obtained by Gomez Vara et al. (1979). They did not observed any changes in sugar content during NA aging.

The total polyphenol content decreased during aging in the three methods (Fig. 3). The initial content was $6.84 \pm 0.12 \mathrm{~g} / \mathrm{l}$ in GAE. In the HTCA and NA methods, the concentration decreased by $13 \%$ and $14 \%$, respectively, at the end of the aging, while in the TCA method, its reduction was $17 \%$. This higher reduction was most likely due to the high temperature and long duration of this method.

\subsection{Sensory Evaluation}

Using ANOVA, significant differences were found between the intensity of the astringency mean value of yerba mate without aging and after aging $(\mathrm{p}<0.002, \mathrm{p}<0.001$ and $\mathrm{p}<0.0017$ for HTCA, TCA and NA, at 45, 120 and 270 days of aging respectively).

Fig. 4 shows the behaviour of astringency in the three aging methods. In HTCA (Fig. 4a), the intensity of astringency increased during aging at the 45 days of aging, but this was not significant with respect to the product without aging. On the other hand, in TCA and NA a decrease of approximately $60 \%$ and $63 \%$ were found (Fig. $4 \mathrm{~b}$ and $4 \mathrm{c}$ ) and they presented significant differences respect to the product without aging. This behaviour was associated with the different aging conditions, resulting in the formation of com- a)

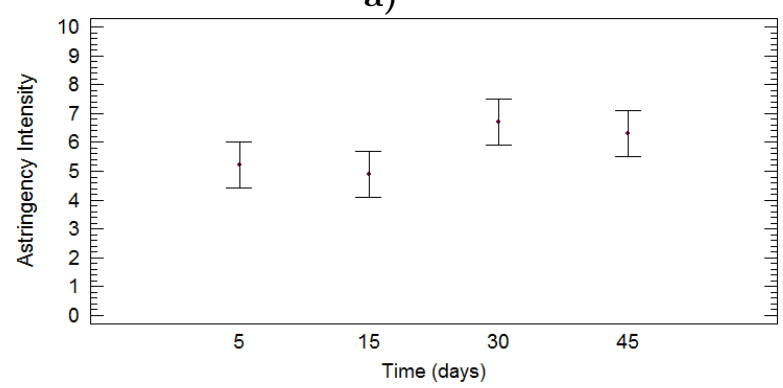

b)

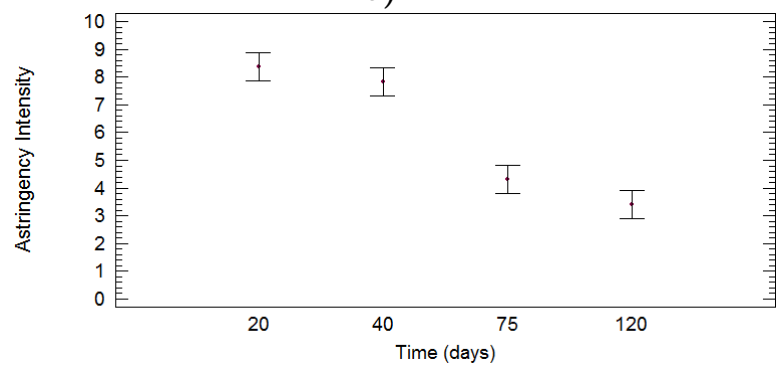

c)

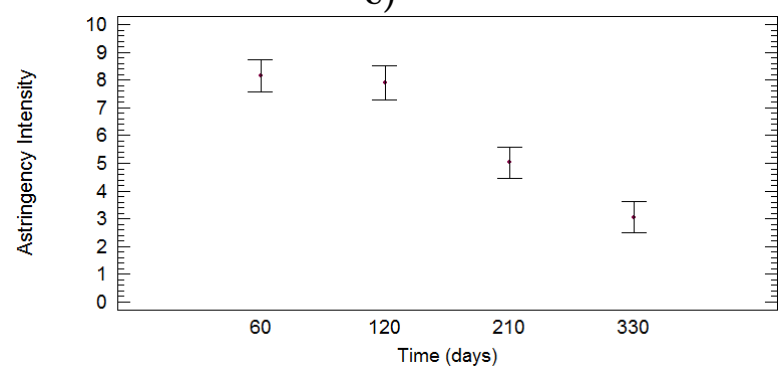

Figure 4: Astringency intensity variation during aging methods: a) HTCA, b) TCA and c) NA.

pounds with different degrees of polymerisation, changing the perception of astringency. Changes in phenolic compounds concentration can modify astringency (Marquez et al., 2013).

For the bitterness, significant differences were found among the three methods with $\mathrm{p}$ values $<0.001$. Bitterness increased with time in all three methods respect to the product without aging (Fig. 5). In HTCA, the bitter intensity increased by $99 \% ; 92 \%$ for TCA and $49 \%$ for NA, at 45,120 and 270 days of aging respectively.

In terms of sweetness, significant differences in intensity were found in the three cases $(p<0.0001)$. No differences were found in the in- 
a)

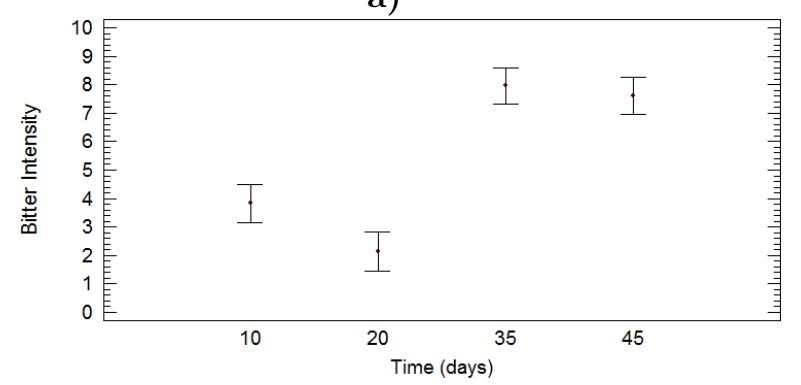

b)

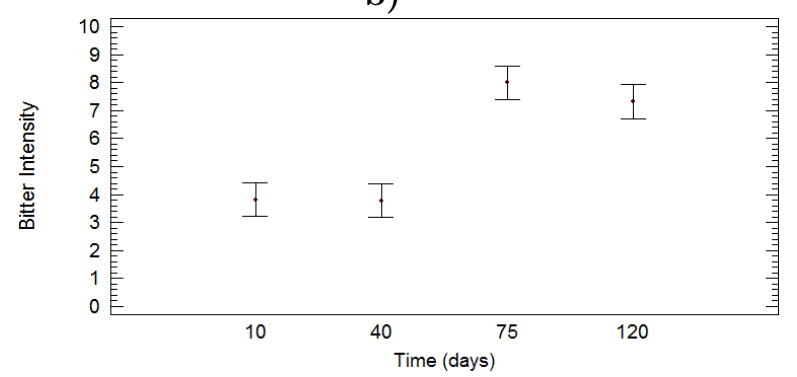

c)

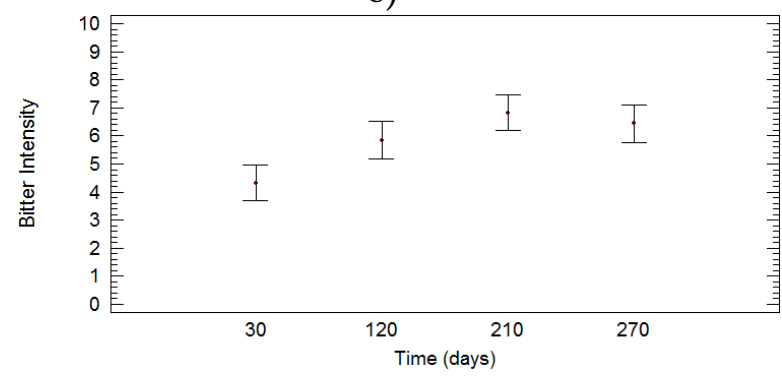

Figure 5: Bitter intensity variation during aging methods: a) HTCA, b) TCA and c) NA.

tensity of sweetness among the three methods of aging. In HTCA, the intensity of sweetness decreased by approximately $37 \%$, in TCA 48 $\%$ and in NA $51 \%$, at 45, 120 and 270 days of aging respectively. The sugar concentration also decreased during aging, but less than the intensity of sweetness. If sugars are expressed as sucrose equivalents (adjusted by their sweetener power), they decreased by $6 \%$ in HTCA, $16 \%$ in TCA and $13 \%$ in NA. This was most likely due to the reduction in the polyphenol and caffeine concentrations.

\subsection{Correlation and Principal Component Analysis}

In the correlation analysis, all component concentrations, $\mathrm{pH}$ and sensory attributes were included. Due to possible reconversion between the different sugar components, a sucrose equivalent concentration was calculated. The same variables were used in the Principal Component Analysis (PCA).

Very few correlations were found between component concentrations (soluble solids, caffeine, sugars and phenolic compounds), $\mathrm{pH}$ and sensory attributes (astringency, bitterness and sweetness). In the HTCA method, only a correlation between astringency and bitterness was found. In the TCA method, correlations between astringencybitterness, pH-sugars and soluble solids-sugars were found. In the NA method, correlations were found between astringency-pH, caffeine-pH and soluble solids-sugars. These results indicated that the sensory attributes were only weakly related to component concentration, and it is not possible to replace sensory evaluation with physicochemical analysis.

In the PCA, only two principal components had eigenvalues greater than 1. In HTCA analysis they explained $100 \%$ of the variance; in TCA, $89 \%$ of the variance and in NA, $91 \%$ of the variance (Fig. 6).

In HTCA (Fig. 6a), PC1 described $78 \%$ of the variance, and almost all variables were included in it. In this case, the bitter and astringent tastes and $\mathrm{pH}$ were inversely related to the polyphenol, sugars and caffeine concentration and sweet taste while PC2 explained $22 \%$ of the variance, mainly including soluble concentration.

In TCA (Fig. 6b), PC1 described $74 \%$ of the variance and almost all variables were included. In this case, the bitter taste and $\mathrm{pH}$ were inversely related to polyphenols, sugars and caffeine concentration and sweet and astringent tastes. PC2 explained $17 \%$ of the variance, through only soluble solids and astringency were of any importance, and they were inversely related.

Finally, in NA, PC1 explained $60 \%$ of the variance (Fig. 6c). The sweet and astringent tastes and $\mathrm{pH}$ and caffeine concentrations were 
a)

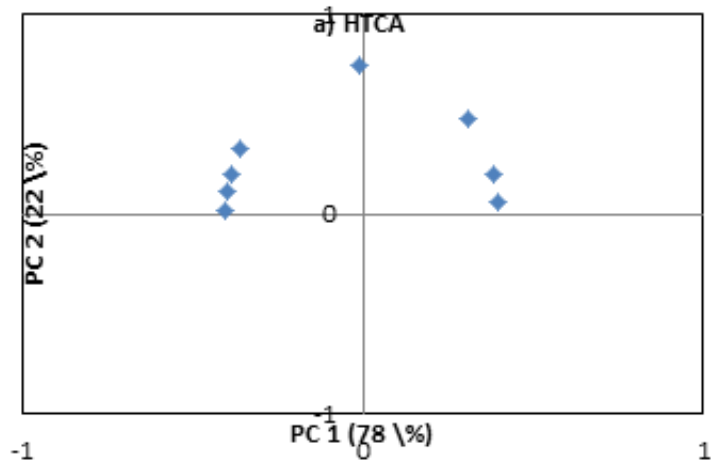

b)

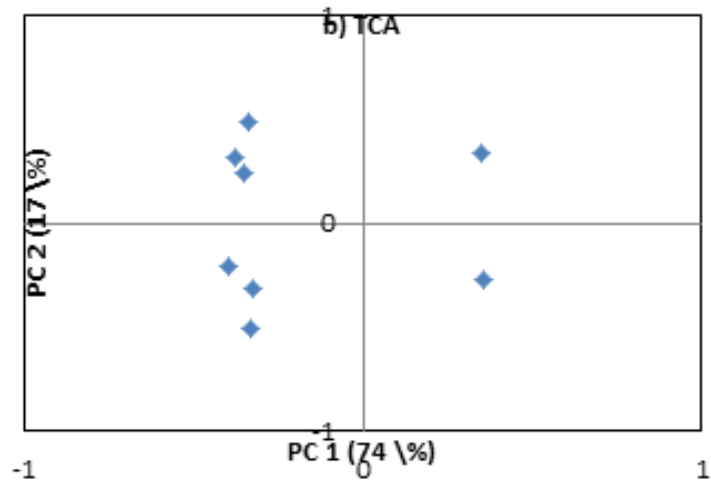

c)

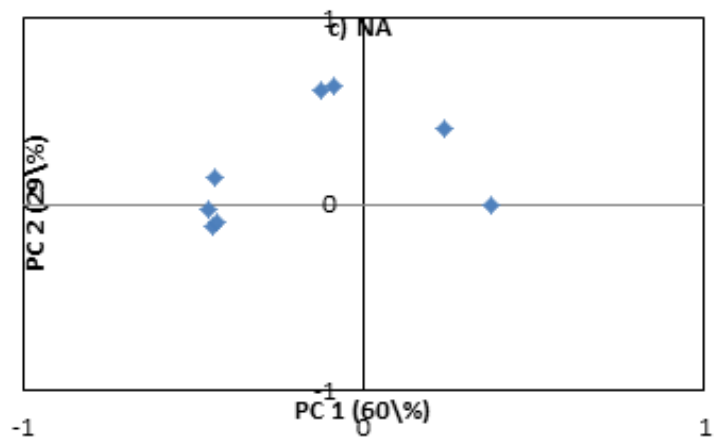

Figure 6: Principal component analysis in the three aging methods: a) HTCA, b) TCA and c) NA (Bitt = bitter; TP = Total Polyphenolic; Sol $=$ Soluble solids; TS $=$ Total sugars Caff $=$ Caffeine; $\mathrm{Sw}=$ Sweet $;$ Ast $=$ Astringency) inversely related to bitter taste and polyphenol concentration, while soluble solids and sugar concentration only influenced PC2.

There was no general pattern of behaviour of independent and dependent variables in the three aging methods, except for bitter and sweet taste that were inversely related in all cases. Generally, the bitter taste was related to the concentration of caffeine and phenolic compounds (Robichaud \& Noble, 1990), but according to the PCA analysis there was an inverse relationship between them in the HTCA and TCA method and a positive relationship in the NA method between the concentration of phenolic compounds and bitter taste.

\section{Conclusions}

During the aging of yerba mate, the concentration of caffeine, glucose, fructose, sucrose, maltose and phenolic compounds and $\mathrm{pH}$ generally decreased in all three methods, namely, HTCA, TCA and NA. The degree of reduction depended on the components and the aging method. Caffeine was the component that had the greatest variation during aging.

The sensory attributes did not show uniform behaviour in the different aging methods. The astringency intensity remained constant in the HTCA method and decreased in the TCA and NA methods. The bitter intensity increased in all three methods but by different percentages. The intensity of the sweetness also diminished in all three methods.

Notably few correlations were determined between component concentrations and sensory tastes. These correlations primarily depend on the aging method. In the principal component analysis, there was no general pattern of behaviour of the independent and dependent variables in relation to the three aging methods, except for bitter and sweet tastes, which were inversely related in all cases.

According to these results, the degree of aging of yerba mate cannot be determined using variations in component concentrations and the sensory method that was actually used, cannot be replaced. 


\section{Acknowledgements}

The authors would like to thank the Instituto Nacional de la Yerba Mate (INYM) from Argentina for funding this research.

\section{References}

Anesini, C., Turner, S., Cogoi, L., \& Filip, R. (2012). Study of the participation of caffeine and polyphenols on the overall antioxidant activity of mate (Ilex paraguariensis). LWT-Food Science and Technologyf, 45(2), 299-304. doi:10.1016/j.lwt.2011.06. 015

Bertoni, M. H., Kricun, S. D. P., Kanzig, R. G., \& Cattaneo, Y. P. (1992). Fresh leaves of Ilex paraguariensis saint hill-iii-influence of the different stages of yerba mate traditional elaboration on the fresh leave composition of clon 44/75, crop 1988. In Anales de la asociación química argentina (Vol. 80, 6, pp. 493-501). ASOC Quimica Argentina Sanchez de Bustamante 1749, 1425 Buenos Aires, Argentina.

Bracesco, N., Sanchez, A. G., Contreras, V., Menini, T., \& Gugliucci, A. (2011). Recent advances on Ilex paraguariensis research: minireview. Journal of Ethnopharmacology, 136(3, SI), 378-384. doi:10.1016/j . jep.2010.06.032

Calvino, A., Fraga, S. G., \& Garrido, D. (2004). Effects of sampling conditions on temporal perception of bitterness in yerba mate (Ilex paraguariensis) infusions. Journal of Sensory Studies, 19(3), 193-210. doi:10.1111/ j.1745-459X.2004.tb00144.x

Dartora, N., de Souza, L. M., Santana-Filho, A. P., Iacomini, M., Valduga, A. T., Gorin, P. A. J., \& Sassaki, G. L. (2011). Uplc-pdams evaluation of bioactive compounds from leaves of Ilex paraguariensis with different growth conditions, treatments and ageing. Food Chemistry, 129(4), 1453-1461. doi:10. 1016/j.foodchem.2011.05.112

de Godoy, R. C. B., Deliza, R., Gheno, L. B., Licodiedoff, S., Frizon, C. N. T., Ribani, R. H., \& dos Santos, G. G. (2013). Consumer perceptions, attitudes and accep- tance of new and traditional mate tea products. Food Research International, 53(2, SI), 801-807. doi:10.1016/j.foodres.2013. 02.054

Gomez Vara, M. E., Brieux, J. A., \& Avanza, J. R. (1979). Investigaciones sobre la tecnología de la yerba mate. Informe APRYMA, 1-226.

Hartwig, V. G., Brumovsky, L. A., \& Fretes, M. R. (2012). A total polyphenol content of mate (Ilex paraguariensis) and other plants-derived beverages. Journal of Food Research, $1(3)$, 58-67.

Heck, C. I. \& De Mejia, E. G. (2007). Yerba mate tea (Ilex paraguariensis): a comprehensive review on chemistry, health implications, and technological considerations. Journal of Sensory Studies, 72(9), R138R151. doi:10.1111/j.1750-3841.2007.00535. $\mathrm{x}$

Holowaty, S. A., Ramallo, L. A., \& Schmalko, M. E. (2012). Intermittent drying simulation in a deep bed dryer of yerba mate. Journal of Food Engineering, $111(1), 110$ 114. doi:10.1016/j.jfoodeng.2012.01.019

Isolabella, S., Cogoi, L., López, P., Anesini, C., Ferraro, G., \& Filip, R. (2010). Study of the bioactive compounds variation during yerba mate (Ilex paraguariensis) processing. Food Chemistry, 122(3), 695-699.

Marquez, V., Martinez, N., Guerra, M., Farina, L., Boido, E., \& Dellacassa, E. (2013). Characterization of aroma-impact compounds in yerba mate (Ilex paraguariensis) using gc-olfactometry and gc-ms. Food Research International, 53(2, SI), 808-815. doi:10.1016/j.foodres.2013.02.016

Pagliosa, C. M., Pereira, S. M., Vieira, M. A., Costa, L. A., Teixeira, E., Amboni, R. D. D. M. C., \& Amante, E. R. (2009). Bitterness in yerba mate (Ilex paraguariensis) leaves. Journal of Sensory Studies, 24(3), 415-426. doi:10.1111/j.1745-459X. 2009.00218.x

Pagliosa, C. M., Vieira, M. A., Podesta, R., Maraschin, M., Bertello Zeni, A. L., Amante, E. R., \& de Mello Castanho Amboni, R. D. (2010). Methylxanthines, phenolic composition, and antioxidant activity of bark from residues from mate tree har- 
vesting (Ilex paraguariensis a. st. hil.) Food Chemistry, 122(1), 173-178. doi:10.1016/j. foodchem.2010.02.040

Robichaud, J. L. \& Noble, A. C. (1990). Astringency and bitterness of selected phenolics in wine. Journal of the Science of Food and Agriculture, 53(3), 343-353. doi:10.1002/ jsfa. 2740530307

Santa Cruz, M. J., Garitta, L. V., \& Hough, G. (2002). Sensory descriptive analysis of yerba mate (Ilex paraguariensis saint hilaire), a south american beverage. Food Science and Technology International, 8(1), 25-31. doi:10.1106/108201302022942

Santa Cruz, M. J., Garitta, L. V., \& Hough, G. (2003). Note: relationships of consumer acceptability and sensory attributes of yerba mate (Ilex paraguariensis st. hilarie) using preference mapping. Food Science and Technology International, 9(5), 347-352. doi:10.1177/108201303038376

Schmalko, M. E. \& Alzamora, S. M. (2001). Color, chlorophyll, caffeine, and water content variation during yerba mate processing. Drying Technology, 19(3-4), 599-610. doi:10.1081/DRT-100103937

Scipioni, G. P., Ferreyra, D. J., Acuna, M. G., \& Schmalko, M. E. (2010). Rebaudioside a release from matrices used in a yerba mate infusion. Journal of Food Engineering, 100(4), 627-633. doi:10 . $1016 / \mathrm{j}$. jfoodeng.2010.05.011

Streit, N. M., Rychecki Hecktheuer, L. H., do Canto, M. W., Mallmann, C. A., Streck, L., Parodi, T. V., \& Canterle, L. P. (2007). Relation among taste-related compounds (phenolics and caffeine) and sensory profile of erva-mate (Ilex paraguariensis). Food Chemistry, 102(3), 560-564. doi:10.1016/j. foodchem.2006.05.028

Tamasi, O. P., Filip, R., Ferraro, G., \& Calviño, A. M. (2007). Total polyphenol content and perceived astringency of yerba mate "Ilex paraguariensis" infusions. Journal of Sensory Studies, 22(6), 653-664. 